\title{
FAKTOR - FAKTOR YANG MEMPENGARUHI STATUS KELENGKAPAN IMUNISASI DASAR DIWILAYAH KERJA PUSKESMAS X KOTA KEDIRI
}

\author{
Gita Sekar Prihanti ${ }^{1}$, Mia Puteri Rahayu ${ }^{2}$, M. Najib Abdullah ${ }^{3}$ \\ Fakultas Kedokteran Universitas Muhammadiyah Malang. \\ J1. Bendungan Sutami 188 A Malang, 65145
}

Email : gitasekarprihanti@gmail.com

\begin{abstract}
ABSTRAK
Latar belakang :Pemberian imunisasi merupakan suatu upaya untuk menimbulkan/meningkatkan kekebalan seseorang secara aktif terhadap suatu penyakit, sehingga bila suatu saat terpajan dengan penyakit tersebut tidak akan sakit atau hanya mengalami sakit ringan. Berdasarkan data di Puskesmas X Kediri tahun 2015, didapatkan beberapa jenis imunisasi yang belum mencapai target misalnya imunisasi HB 0-7 hari (target 91\% dengan pencapaian sebesar 90,5\%), imunisasi DPT/ HB 1 (target 95\% dengan pencapaian 89,5\%), Imunisasi DPT/HB 3 (target 90\% dengan pencapaian sebesar 79\%), dan imunisasi campak (target 90\% dengan pencapaian 83,7\%). Angka dropout imunisasi DPT/HB 1 - Campak ditargetkan sebesar $\pm 5 \%$, namun pencapaiannya sebesar $-14,9 \%$. Sedangkan Angka dropout DPT/HB 1 - DPT/HB 3 juga ditargetkan $\pm 5 \%$, namun pencapaiannya sebesar $-14,9 \%$. Pada anak usia kelas 1 SD dilakukan imunisasi DPT dengan target sebesar 98\% dari 409 jiwa, pencapaiannya masih kurang dari target yaitu sebesar 398 jiwa atau 97,3\%. Imunisasi campak pada anak kelas 1 SD juga ditargetkan mencapai 98\% dari 402 jiwa namun pencapaiannya masih kurang yaitu sebesar 388 jiwa atau 96,5\%. Tujuan :Mengidentifikasi faktor-faktor yang mempengaruhi kelengkapan imunisasi dasar di Wilayah kerja Puskesmas $\mathrm{X}$ Kediri.Metode : Desain case-control. Pengambilan sampel dengan teknik simple random sampling. Jumlah sampel 84 orang. Data diperoleh register kohort bayi tahun 2015 - Juli 2016 Pasien Imunisasi di Wilayah Kerja Puskesmas X Kota Kediri. Hasil penelitian ::Hasil uji regresi logistik biner menunjukkan bahwa terdapat empat variabel yang mempunyai pengaruh signifikan terhadap kelengkapan imunisasi dasar, yaitu usia $(\mathrm{p}=0,029 ; \mathrm{CI}=0,012-0,955 ; \mathrm{OR}=0,106)$,pekerjaan $(\mathrm{p}=0,026$; $\mathrm{CI}=1,300-9,539 ; \mathrm{OR}=3,521)$, Pengetahuan $(\mathrm{p}=0,019 ; \mathrm{CI}=0,054-0,928 ; \mathrm{OR}=0,224)$, dan kehadiran balita $(\mathrm{p}=0,00 ; \mathrm{CI}=-; \mathrm{OR}=$ -).Berdasarkan nilai adjusted $R$ square yaitu 0,354 (35,4\%). Faktor yang paling dominan berpengaruh terhadap kelengkapan imunisasi, ditunjukkan oleh nilai $\beta$ tertinggi, yaitu faktor pekerjaan $(\beta=1,590)$.Sedangkan faktor yang tidak signifikan diantaranya pendidikan $(p=0,309)$, Pendapatan $(p=0,378)$, Sikap $(p=0,057)$, dan Peran petugas $(p=$ constant $)$. Kesimpulan :Faktor-faktor yang mempengaruhi status kelengkapan imunisasi dasar di wilayah kerja Puskesmas X Kota Kediri meliputi faktor predisposisi(predisposing) yaitu usia, pekerjaan dan pengetahuan. Tidak ada hubungan antara faktor penguat (reinforcing) dan faktor pemungkin (enabling) denganstatus kelengkapan imunisasi dasar.
\end{abstract}

Kata Kunci : Faktor yang mempengaruhi status kelengkapan imunisasi dasar, wilayah kerja Puskesmas X Kota Kediri. 


\section{ABSTRACT}

Background :Immunization is an attempt to induce / increase one's immunity is active against a disease, so that if one day be exposed to the disease will not be ill or suffered only mild illness. Based on the data in PuskesmasX 2015, obtained some type of immunization that have not reached the target as immunization HB 0-7 days (target 91\% achievement of 90.5\%), DPT / HB 1 (target 95\% by attaining $89.5 \%$ ), immunization DPT / HB 3 (target of 90\% with the achievement of 79\%), and measles immunization (target of $90 \%$ by attaining $83.7 \%$ ). Dropout rates DPT / HB 1 - Measles is targeted at \pm 5\%, but the achievement of - 14.9\%. While Dropout rates DPT / HB 1 - DPT / HB 3 also targeted $\pm 5 \%$, but the achievement of - 14.9\%. At age children in 1st grade, DPT immunization with a target of $98 \%$ of 409 people, achievement is still less than the target in the amount of 398 people or $97.3 \%$. Immunization against measles in children in 1st grade, also targeted to reach 98\% of 402 inhabitants but its achievements are still lacking in the amount of 388 people or 96.5\%. Objective: Identify the factors that affect the completeness of basic immunization in Puskesmas working area X. Methods:this study used case-control design. Study sampling with simple random sampling technique. Number of samples 84 . Data obtained register cohort of babies 2015 - July 2016 Patient immunization in PuskesmasX Kediri. Result:: binary logistic regression test results indicate that there are four variables that have a significant influence on the completeness of basic immunization, the age $(p=0.029$; $C I=0.012$ to 0.955; OR = 0.106), occupation $(p=0.026 ; C I=1,300$-9.539; OR = 3.521), knowledge $(p=0.019 ; C I=0.054$ to 0.928; OR = 0.224), and the presence of infants $(p=0.00 ; C I=-; O R=-)$.Based on the adjusted R-square: $0.354(35.4 \%)$, the most dominant factor that affect the completeness of immunization, indicated by the highest $\beta$, ie work factor $(\beta=1.590)$. While not significant factors include education $(p=0.309)$, Revenue $(p=0.378)$, attitude $(p=0.057)$, and the officer's role $(p=$ constant). Conclusions: Factors affecting the completeness status of basic immunization in Puskesmas $X$ of Kediri include predisposing factors (predisposing) ie age, occupation and knowledge. There is no correlation between the amplifier (reinforcing) and enabling factors (enabling) the completeness of basic immunization status.

Keywords : Factors affecting the completeness of basic immunization status, PuskesmasX Kediri.

\section{PENDAHULUAN}

Imunisasi adalah suatu upaya untuk menimbulkan/meningkatkan kekebalan seseorang secara aktif terhadap suatu penyakit, sehingga bila suatu saat terpajan dengan penyakit tersebut tidak akan sakit atau hanya mengalami sakit ringan. Pemberian imunisasi merupakan tindakan pencegahan agar tubuh tidak terjangkit penyakit infeksi tertentu seperti tetanus, batuk rejan (pertusis), campak (measles), polio dan tuberkulosis. ataumeskipun terkena penyakit, tidak memberikan akibat yang fatal bagi tubuh (Dinas Kesehatan, 2013).

Berdasarkan data di Puskesmas X tahun 2015, sasaran imunisasi di daerah tersebut sebanyak 325 jiwa bayi, Target imunisasi HB 0-7 hari yaitu $91 \%$, sedangkan pencapaian imunisasi HB 0-7 hari sebanyak 294 jiwa bayi (90,5\%). Imunisasi BCG targetnya $95 \%$, sedangkan pencapaian imunisasi BCG sebanyak 316 jiwa bayi $(97,2 \%)$. Imunisasi DPT/HB 1 pada bayi targetnya sebesar 95\%, sedangkan pencapaian imunisasi DPT/HB 1 sebanyak 291 jiwa bayi (89,5\%). Imunisasi DPT/
HB 3 target yang harus dicapai sebesar 90\%, sedangkan pencapaian imunisasi DPT/HB 3 sebesar 257 jiwa bayi (79\%). Imunisasi campak target yang harus dicapai sebesar $90 \%$, sedangkan pencapaian imunisasi campak sebesar 272 jiwa bayi $(83,7 \%)$. Dalam penyelenggaraan imunisasi dasar tahun 2015 didapatkan beberapa jenis imunisasi yang belum mencapai target misalnya imunisasi HB 0-7 hari (target 91\% dengan pencapaian sebesar 90,5\%), imunisasi DPT/HB 1 (target 95\% dengan pencapaian 89,5\%), Imunisasi DPT/HB 3 (target $90 \%$ dengan pencapaian sebesar 79\%), dan imunisasi campak (target 90\% dengan pencapaian 83,7\%). Angka dropout imunisasi DPT/HB 1 - Campak ditargetkan sebesar $\pm 5 \%$, namun pencapaiannya sebesar - 14,9\%. Sedangkan Angka dropout DPT/ HB 1 - DPT/HB 3 juga ditargetkan $\pm 5 \%$, namun pencapaiannya sebesar - 14,9\%. Pada anak usia kelas 1 SD dilakukan imunisasi DPT dengan target sebesar 98\% dari 409 jiwa, pencapaiannya masih kurang dari target yaitu sebesar 398 jiwa atau 97,3\%. Imunisasi campak pada anak kelas $1 \mathrm{SD}$ juga ditargetkan mencapai 98\% dari 402 jiwa namun pencapaiannya masih kurang yaitu sebesar 388 jiwa 
atau 96,5\%. (Laporan Kinerja Puskesmas X , 2015).

\section{METODE}

Penelitian ini bersifat observasional analitik dengan desain case control untuk mengumpulkan data populasi dengan mengambil data masa yang lampau.Penelitian ini dilakukan di wilayah kerja Puskesmas X Kediri pada bulan September 2016.

Populasi dari penelitian ini adalah seluruh ibu dengan bayi yang mengukuti imunisasi dasar di Wilayah Kerja Puskesmas X .Sampel dipilih menggunakan teknik Simple random sampling.Sampel dalam penelitian ini berjumlah 84 orang.

Metode pengumpulan data primer diperoleh melalui wawancara dengan menggunakan kuesioner. Kemudian dilakukan uji validitas dan reliabilitas. Setelah itu dilakukan pengolahan data.

\section{HASIL}

Telah dilakukan penelitian terhadap populasi yang ditentukan. Data yang diperoleh merupakan data primer yang diambil melalui wawancara dengan metode kuesioner kepada ibu yang memiliki bayi yang mengikuti imunisasi dasar di wiayah kerja puskesmas X Kediri periode tahun 2015 Juli 2016.

Dari data registrasi kohort bayi tahun 2015 hingga juli 2016 didapatkan 42 bayi dengan status imunisasi tidak lengkap. Kemudian diambil data 42 bayi dengan status imunisasi lengkap, sehingga sampel yang digunakan sebanyak 84 bayi.

Berdasarkan usia ibu pada kelompok imunisasi tidak lengkap didapatkan ibu dengan usia $<25$ tahun sebanyak 42 orang $(48,8 \%)$, yang berusia e" 25 tahun sebanyak 1 orang $(1,2 \%)$. Sedangkan pada kelompok dengan imunisasi lengkap yang didapatkan ibu dengan usia <25 tahun sebanyak 34 orang (40,5\%), yang berusia e" 25 tahun sebanyak 8 orang $(9,5 \%)$.

Berdasarkan Tingkat pendidikan didapatkan pada kelompok imunisasi tidak lengkap (dropout) pendidikan tinggi yaitu sebanyak 6 orang $(7,1 \%)$, pendidikan menengah sebanyak 18 orang $(21,4 \%)$, dan pendidikan rendah sebanyak 18 orang $(21,4 \%)$. Sedangkan pada kelompok imunisasi lengkap pendidikan tinggi yaitu sebanyak 4 orang $(4,8 \%)$, pendidikan menengah sebanyak 25 orang $(29,8 \%)$, dan pendidikan rendah sebanyak 13 orang $(15,5 \%)$.

Berdasarkan pekerjaan ibu didapatkan pada kelompok imunisasi tidak lengkap (dropout) sebanyak 22 orang $(26,2 \%)$ bekerja, dan 20 orang $(23,8 \%)$ tidak bekerja.Sedangkan pada kelompok imunisasi lengkap sebanyak 12 orang bekerja (14,3\%), dan 30 orang tidak bekerja $(35,7 \%)$.

Berdasarkan tingkat pendapatan, diketahui jumlah responden pada kelompok imunisasi tidak lengkap (dropout) pendapatanmenengah yaitu sebanyak 20 orang $(23,8 \%)$, dan pendapatan rendah sebanyak 22 orang $(26,2 \%)$. Sedangkan pada kelompok imunisasi lengkap pendapatanmenengah yaitu sebanyak 16 orang (19\%), dan pendapatan rendah sebanyak 26 orang $(31 \%)$.

Berdasarkan pengetahuan, diketahui jumlah responden pada kelompok imunisasi tidak lengkap (dropout) pengetahuan kurang yaitu sebanyak 11 orang $(13,1 \%)$ dan pengetahuan baik sebanyak 31 orang $(31 \%)$. Sedangkan pada kelompok imunisasi lengkap pengetahuan kurang yaitu sebanyak 3 orang $(3,6 \%)$ dan pengetahuan baik sebanyak 39 orang $(46,4 \%)$.

Berdasarkan sikap ibu, diketahui jumlah responden pada kelompok imunisasi tidak lengkap (dropout) sikap kurang yaitu sebanyak 7 orang $(8,3 \%)$ dan sikap baik sebanyak 35 orang $(41,7 \%)$. Sedangkan pada kelompok imunisasi lengkap sikap kurang yaitu sebanyak 1 orang $(1,2 \%)$ dan sikap baik sebanyak 41 orang $(48,8 \%)$.

Berdasarkan peran petugas kesehatan, diketahui jumlah responden pada kelompok imunisasi tidak lengkap (dropout)peran petugas dinyatakan aktif yaitu sebanyak 42 orang (50\%). Sedangkan pada kelompok imunisasi lengkapperan petugas dinyatakan aktif yaitu sebanyak 42 orang $(50 \%)$.

\section{Analisis Bivariat}

Analisis bivariat digunakan dengan tujuan untuk mengetahui faktor-faktor yang berhubungan dengan status kelengkapan imunisasi dasar, dengan menggunakan rumus Chi-square. 


\section{FAKTOR- FAKTOR YANG MEMPENGARUHI KELENGKAPAN IMUNISASI 123}

Tabel 5.3 Analisis Bivariat Uji Chi-square antara Variabel Independen terhadap Dependen

\begin{tabular}{|c|c|c|c|c|c|c|c|}
\hline \multirow[b]{2}{*}{ Faktor Resiko } & \multicolumn{2}{|c|}{ DO } & \multicolumn{2}{|c|}{ Imunisasi len gkap } & \multirow[b]{2}{*}{ OR } & \multirow[b]{2}{*}{$95 \% \mathrm{CI}$} & \multirow[b]{2}{*}{$\mathbf{P}$} \\
\hline & Jumlah & $\begin{array}{l}\text { Prosent } \\
\text { asi (\%) }\end{array}$ & Jumlah & $\begin{array}{c}\text { Prosentasi } \\
(\%)\end{array}$ & & & \\
\hline \multicolumn{8}{|l|}{ Usia } \\
\hline$<25$ tahun & 41 & 48,8 & 34 & 40,5 & 0,106 & $(0,012-0.955)$ & 0,029 \\
\hline$=25$ tahun & 1 & 1,2 & 8 & 9,5 & & & \\
\hline \multicolumn{8}{|l|}{ Pendidikan } \\
\hline Rendah & 18 & 21,4 & 13 & 15,5 & & & 0,309 \\
\hline Menengah & 18 & 21,4 & 25 & 29,8 & - & - & \\
\hline Tinggi & 6 & 7,1 & 4 & 4,8 & & & \\
\hline \multicolumn{8}{|l|}{ Pekerjaan } \\
\hline Tidak Bekerja & 20 & 23,8 & 30 & 35,7 & 3,521 & $(1,300-9,539)$ & 0.026 \\
\hline Bekerja & 22 & 26,2 & 12 & 14,3 & & & \\
\hline \multicolumn{8}{|l|}{ Pendapatan } \\
\hline Rendah & 22 & 26,2 & 26 & 31 & & & 0,378 \\
\hline Menegah & 20 & 23,8 & 16 & 19 & - & - & \\
\hline \multicolumn{8}{|l|}{ Pengetahu an } \\
\hline Kurang & 11 & 13,1 & 3 & 3,6 & & & 0,019 \\
\hline Baik & 31 & 36,9 & 39 & 46,4 & 0,224 & $(0,054-0,928)$ & \\
\hline \multicolumn{8}{|l|}{ Sikap } \\
\hline Kurang & 7 & 8,3 & 1 & 1,2 & - & - & 0,057 \\
\hline Baik & 35 & 41,7 & 41 & 48,8 & & & \\
\hline \multicolumn{8}{|l|}{ Peran Petugas } \\
\hline Aktif & 42 & 50 & 42 & 50 & - & - & Constant \\
\hline Pasif & 0 & 0 & 0 & 0 & & & \\
\hline \multicolumn{8}{|l|}{ Kehadiran } \\
\hline Tidak Hadir & 42 & 50 & 0 & 0 & - & - & 0,00 \\
\hline Hadir & 0 & 0 & 42 & 50 & & & \\
\hline
\end{tabular}

(Sumber : Data yang diolah, 2016)

Berdasarkan tabel di atas diketahui hasil uji chi-square pada analisis bivariat menunjukkan empat variabel yang mempunyai pengaruh signifikan terhadap perilaku kunjungan ibu ke posyandu, yaitu usia $(p=0,029)$, pekerjaan $(p=0,026)$, Pengetahuan $(\mathrm{p}=0,019)$, dan kehadiran balita $(\mathrm{p}=0,000)$.

\section{Analisis Multivariat}

Analisis multivariat bertujuan untuk melihat pengaruh antara beberapa variabel independen terhadap dependen. Adapun hasil penguijan variabelvariabel independen tersebut dengan menggunakan uji regresi logistik biner tampak seperti tabel di bawah ini.
Tabel 5.3.2. Analisis Multivariat Uji Regresi Logistik Biner antara Variabel Independen terhadap Dependen

\begin{tabular}{|c|c|c|c|c|}
\hline & V ariable & $\begin{array}{l}\text { K } \\
\text { o e } \\
\text { fi s } \\
\text { i e } \\
\text { n }\end{array}$ & $P$ & O R $\quad\left(\begin{array}{llll}9 & 5 \% & \mathrm{C} & \mathrm{I}\end{array}\right)$ \\
\hline \multirow[t]{4}{*}{$\begin{array}{l}\mathrm{V} \text { aria } \\
\text { be } 1\end{array}$} & Pengetah ua n & $\begin{array}{c}- \\
1 \\
49 \\
7\end{array}$ & 0,039 & $\begin{array}{c}0,224\left(\begin{array}{ccccc}0,05 & 4 & - \\
0,9 & 2 & 8\end{array}\right)\end{array}$ \\
\hline & P ekerjaa $n$ & $\begin{array}{c}1 \\
25 \\
9\end{array}$ & 0,013 & $\left.\begin{array}{ccccccc}3,52 & 1 & (1,3 & 0 & 0 & - \\
& 9,5 & 3 & 9\end{array}\right)$ \\
\hline & U s i a & $\begin{array}{c}- \\
2, \\
24 \\
6\end{array}$ & 0,045 & $\begin{array}{c}0,106\left(\begin{array}{llll}0,0 & 1 & 2 & - \\
0,95 & 5\end{array}\right)\end{array}$ \\
\hline & $\mathrm{K}$ onstanta & $\begin{array}{c}1, \\
53 \\
2\end{array}$ & & \\
\hline
\end{tabular}

(Sumber : Data primer yang diolah, 2016) 
Uji regresi logistik ini menunjukkan bahwa variabel yang berpengaruh terhadap kelengkapan imunisasi adalah pekerjaan, pengetahuan dan usia. Artinya bila seorang ibu bekerja atau memiliki pengetahuan yang kurang atau usianya $<25$ tahun maka akan berpengaruh terhadap kelengkapan imunisasi anaknya.

Kekuatan hubungan dapat dilihat dari nilai Odd Ratio (OR). Kekuatan hubungan dari yang terbesar ke yang terkecil adalah pekerjaan $(\mathrm{OR}=3,521)$, pengetahuan $(\mathrm{OR}=0,224)$ dan usia $(\mathrm{OR}=0,106)$. Variabel pekerjaan memiliki resiko 3,52 kali $(\mathrm{OR}=3,521)$ terhadap kelengkapan imunisasi anak, dimana nilai CI antara 1,300 9,539 (rentang $\mathrm{CI}>1$ ). Artinya bila seorang ibu tidak bekerja maka kemungkinan ibu untuk melakukan imunisasi lengkap akan 3,52 kali lebih besar dibandingkan dengan ibu yang bekerja.

Variabel pengetahuan memiliki resiko 0,22 kali $(\mathrm{OR}=0,224)$ terhadap kelengkapan imunisasi, dengan nilai CI antara 0,054 - 0,928 (rentang $\mathrm{CI}<1$ ). Artinya bila seorang ibu memiliki pengetahuan yang baik maka kemungkinan untuk melakukan imunisasi lengkap akan ditekan 0,22 kali dibandingkan dengan ibu yang pengetahuannya kurang.

Variabel usia memiliki resiko 0,10 kali $(\mathrm{OR}=0,106)$ terhadap kelengkapan imunisasi, dengan nilai CI antara $0,012-0,955$ (rentang $\mathrm{CI}<1$ ). Artinya bila seorang ibu memiliki usia $>25$ tahun maka kemungkinan untuk melakukan imunisasi lengkap akan ditekan 0,10 kali dibandingkan dengan ibu yang berusia $<25$ tahun.

Berdasarkan nilai koefesien masing-masing variable dari tabel 5.3.2 diperoleh persamaan regresi logistik sebagai berikut :

$\mathrm{Y}=$ konstanta $+\mathrm{a}_{1} \mathrm{x}_{1}+\mathrm{a}_{2} \mathrm{x}_{2}+\ldots+\mathrm{a}_{\mathrm{i}} \mathrm{x}_{\mathrm{i}}$

$\mathrm{Y}=1,532+(-2,246)$ (Usia) $+1,259$ (Pekerjaan)

$+(-1.497)$ (pengetahuan)

Nilai variabel bebas : usia : $0=<25 ; 1=>25$ th

Pekerjaan: $0=$ bekerja; $1=$ tidak bekerja

Pengetahuan: $0=$ kurang ; $1=$ baik

Aplikasi dari hasil persamaan yang diperoleh adalah untuk memprediksi berapa besar faktorfaktor yang ada memberikan pengaruh terhadap kelengkapan imunisasi dengan menggunakan rumus:

$\mathrm{P}=1 /\left(1+\mathrm{e}^{-\mathrm{y}}\right)$

Dimana, $\mathrm{p}=$ probabilitas untuk terjadinya suatu kejadian

$\mathrm{e}=$ bilangan natural $=2.7$

$\mathrm{y}=$ konstanta $+a_{t} X_{1}+a_{2} X_{2}+\ldots \ldots \ldots \ldots+a_{i} X_{i}$

$\mathrm{a}=$ nilai koefisien tiap variabel

$\mathbf{x}=$ nilai variabel bebas

Hasil prediksi dari persamaan di atas dapat dilihat pada tabel 5.3.3

Tabel 5.3.3 Probabilitas faktor-faktor yang mempengaruhi kelengkapan imunisasi

\begin{tabular}{|c|c|c|c|}
\hline Variabel 1 & Variabel 2 & Variabel 3 & $\begin{array}{c}\text { Probabilitas } \\
(\mathrm{P})\end{array}$ \\
\hline Usia $<25$ & Bekerja & Pengetahuan kurang & 0,82 \\
\hline Usia $>25$ & Bekeria & Pengetahuan kurang & 0,49 \\
\hline Usia $<25$ & $\begin{array}{c}\text { TIdak } \\
\text { Bekerja }\end{array}$ & Pengetahuan kurang & 0,94 \\
\hline Usia $<25$ & Bekeria & Pengetahuan baik & 0,51 \\
\hline Usia $>25$ & Tidak bekerja & Pengetahuan baik & 0,28 \\
\hline
\end{tabular}

Sumber : data yang diolah tahun 2016

Hasil penghitungan probabilitas faktor yang mempengaruhi kelengkapan imunisasi menunjukkan bahwa bila seorang ibu berusia $>25$ tahun,bekerja dan memiliki pengetahuan yang kurang maka kemungkinan drop out sebesar $82 \%(\mathrm{P}=0,82)$. Ibu yang berusia $>25$ tahun, bekerja dan pengetahuannya kurang memiliki kemungkinan drop out sebesar $49 \%(\mathrm{P}=0,49)$. Ibu yang berusia $<25$ tahun, tidak bekerja dan pengetahuannya kurang maka kemungkinan drop out sebesar 94\% $(\mathrm{P}=0$,94). Ibu dengan usia $<25$ tahun, bekerja dan pengetahuannya baik memiliki kemungkinan drop out sebesar 51\% ( $\mathrm{P}=0,51)$.Ibu dengan usia $>25$ tahun,tidak bekerja dan pengetahuannya baik memiliki kemungkinan drop out sebesar 28\% $(\mathrm{P}=0,28)$.

\section{DISKUSI}

Tujuan utama kegiatan imunisasi adalah menurunkan angka kesakitan dan kematian akibat Penyakit yang Dapat Dicegah Dengan Imunisasi (PD3I). PD3Iadalah penyakit-penyakit menular yang sangat potensial untuk menimbulkan wabahdan 
kematian terutama pada balita. Berdasarkan data cohort bayi periode tahun 2015 sampai juli 2016 didapatkan data bayi dengan dropout imunisasi sebanyak 53 bayi. Namun setelah dilakukan penelitian didapatkan 11 yang keluar dari penelitian karena bayi pindah rumah ( 9 bayi), dan bayi telah melakukan imunisasi di tempat lain (2 bayi). Sehingga sampel penelitian menjadi 42 bayi dengan status imunisasi dasar tidak lengkap (dropont).

Berdasarkan analisis bivariat dengan uji Fisher's exact test sebagai alternatif dari uji chi square karena distribusi data tidak memenuhi syarat uji $c h i$ square. Didapatkan hasil dengan signifikansi sebesar $0,029(p<0,05)$, artinya usia memiliki pengaruh secara signifikan dalam menyebabkan dropout imunisasi. Hal ini tidak sesuai dengan penelitian yang dilakukan oleh Nugroho (2012) dengan hasil uji chi square menunjukkan nilai $(\mathrm{p}=0,82>0,05)$, dimana tidak ditemukan hubungan yang signifikan antara usia ibu dengan kelengkapan imunisasi dasar.

Usia merupakan salah satu sifat karakteristik orang yang sangat utama, usia juga mempunyai hubungan yang sangat erat dengan berbagai sifat orang lainnya, dan juga mempunyai hubungan erat dengan tempat dan waktu (Rahmawati, 2014). Dalam penelitian ini ditemukan usia ibu $<25$ tahun paling banyak ditemukan pada kelompok imunisasi dasar tidak lengkap (dropout) yaitu sebesar 41 responden $(48,8 \%)$. Usia ibu yang lebih muda umumnya dapat mencerna informasi tentang imunisasi lebih baik dibanding dengan usia ibu yang lebih tua. Ibu yang berusia lebih muda dan baru memiliki anak biasanya cenderung untuk memberikan perhatian yang lebih akan kesehatan anaknya, termasuk pemberian imunisasi (Ikawati, 2011). Namun pada wilayah $X$ justru ibu dengan usia lebih tua (e" 25 tahun) yang memiliki anak dengan status imunisasi lebih lengkap. Hal ini juga menjelaskan bahwa usia ibu yang mengalami peningkatan dalam batas tertentu maka dapat meningkatkan pengalaman ibu dalam mengasuh anak, sehingga akan berpengaruh dalam upaya pencegahan dan penanggulangan timbulnya penyakit (Rizqiawan, 2008).

Berdasarkan analisis bivariat dengan uji $c h i$ square dan ditemukan hasil dengan signifikansi sebesar 0,019 ( $\mathrm{p}<0,05)$, artinya ditemukan hubungan yang bermakna antara pengetahuan dan sikap terhadap kelengkapan imunisasi dasar. hal ini sejalan dengan penelitian yang dilakukan Rizani
(2010) bahwa terdapat hubungan antara pengetahuan dengan perilaku dalam pemberian imunisasi.

Pengetahuan dapat diartikan sebagai kumpulan informasi yang dapat dipahami dan diperoleh dari proses belajar selama hidup dan dapat dipergunakan sewaktu-waktu sebagai alat untuk penyesuaian diri. Pengetahuan merupakan pengenalan terhadap kenyataan, kebenaran, prinsip dan kaidah suatu objek dan merupakan hasil stimulasi untuk terjadinya perubahan perilaku. Pengetahuan ibu tentang imunisai akan mempengaruhi keyakinan dan sikap ibu dalam kepatuhannya terhadp imunisasi. Kepatuhan terhadap perilaku pencegahan yang berkaitan dengan dunia medis merupakan fungsi dari keyakinantentang kesehatan, ancaman yang dirasakan, persepsi kekebalan, pertimbangan mengenaihambatan atau kerugian (misalnya biaya dan waktu), serta keuntungan yaitu efektivitas dari anjuran medis tersebut (Rizani, 2010).

Menurut WHO tentang analisis penyebab seseorang berperilaku tertentu salah satunya yaitu pengetahuan. Apabila suatu program interventif seperti imunisasi ingin dilaksanakan secara serius dalam menjawab perubahan pola penyakit maka perbaikan dalam evaluasi perilaku kesehatan masyarakat dan peningkatan pengetahuan sangat dibutuhkan (Rabmawati, 2014).

Berdasarkan analisis bivariat dengan ujichi square dengan hasil signifikansi sebesar 0,026 $(p<$ $0,05)$, artinya pekerjaan memiliki pengaruh secara signifikan dalam menyebabkan dropout imunisasi. Hasil ini tidak sesuai dengan penelitian yang dilakukan oleh Rahmawati (2014) dimana tidak ditemukan hubungan antara status pekerjaan dengan kelengkapan imunisasi. Tidak adanya pengaruh ini dikarenakan terdapat kesamaan antara responden yang memiliki anak dengan status imunisasi lengkap maupun tidak lengkap yang sebagian besar tidak bekerja atau hanya sebagai ibu rumah tangga. Sehingga tidak terdapat persebaran status pekerjaan responden. Sedangkan pada penelitian yang kami kerjakan didapatkan perbedaan jumlah responden yang bekerja pada kelompok dropout imunisasi (22 responden) dibandingkan responden yang bekerja pada kelompok imunisasi lengkap (12 responden).

Teori kebutuhan (teori Maslow) mengemukakan nilanya 5 tingkat kebutuhan pokok manusia. Kelima tingkat ilmiah yang kemudian 
dijadikan pengertian guna dalam mempelajari motivasi manusia. Kelima tingkatan tersebut adalah kebutuhan fisiologis, kebutuhan rasa aman dan perlindungan, kebutuhan sosial, kebutuhan penghargaan, kebutuhan aktivitas diri. Ibu yang mempunyai pekerjaan itu demi mencukupi kebutuhan keluarga (kebutuhan pertama) akan mempengaruhi kegiatan imunisasi yang termasuk kebutuhan rasa aman dan perlindungan sehingga ibu lebih mengutamakan pekerjaan dari pada mengantarkan bayinya untuk di imunisasi (Purwanto, 2000).

Berdasarkan penelitian yang telah dilakukan diketahui bahwa pada kelompok imunisasi tidak lengkap (dropout) didapatkan 42 responden mengatakan bahwa peran petugas kesehatan baik (aktif). Sedangkan pada kelompok imunisasi lengkap juga mendapatkan 42 responden mengatakan peran petugas kesehatan baik (aktif). Hal ini menunjukkan bahwa tidak ada perbedaan antara peran petugas kesehatan terhadap bayi yang drop out dan bayi yang lengkap status imunisasinya sehingga dalam uji statistik nilai signifikan vaariabel ini menjadi 0.000 .

Menurut penelitian yang dilakukan oleh vidia (2013) dengan menggunakan uji fisher diperoleh nilai $\mathrm{p}$ value $=1,000(\mathrm{p}>0,05)$ maka dinyatakan tidak ada hubungan antara peran petugas kesehatan terhadap kelengkapan imunisasi dasar. Sedangkan berdasarkan teori yang dikemukakan oleh Effendi dalam Mulati (2009) menyatakan peran adalah tingkah laku yang diharapkan seseorang dengan kedudukan dalam sistem, dimana dapat dipengaruhi oleh keadaan sosial yang konstan. Seorang petugas kesehatan mempunyai peran sebagai seorang pendidik, peran ini dilakukan dengan membantu klien dan keluarga dalam meningkatkan tingkat pengetahuan kesehatan, gejala penyakit, bahkan tindakan yang diberikan, sehingga terjadi perubahan perilaku klien dan keluarga setelah dilakukan pendidikan kesehatan selain itu juga petugas kesehatan merupakan tempat konsultasi terhadap masalah atau perilaku kesehatan yang didapat (Mulati, 2009).

Berdasarkan analisis bivariat dengan ujiFisher's Exact Test sebagai alternative uji chi square dengan hasil signifikansi sebesar 0,057 ( $>$ > 0,05), artinya tidak ditemukan hubungan yang bermakna antara sikap terhadap kelengkapan imunisasi. Hasil ini tidak sesuai dengan penelitian Ali (2003) yang berjudul "Pengetahuan, Sikap, dan Perilaku Ibu Bekerja dan Ibu tidak Bekerja tentang Imunisasi" dimana dari penelitian tersebut juga terbukti terdapat hubungan yang bermakna antara sikap dengan kelengkapan imunisasi dengan nilai $\mathrm{p}=0,007$. Responden penelitian, yaitu ibu, bisa menyebabkan tidak adanya hubungan antara sikap dengan status imunisasi balita. Hal ini dikarenakan tidak semua ibu mengantarkan anaknya ke posyandu untuk diberikan imunisasi. Ada beberapa balita yang pergi ke posyandu diantarkan oleh pengasuh, nenek, bahkan ayah balita sendiri. Hal ini mengakibatkan peran ibu dalam pemberian imunisasi balita lebih sedikit dibandingkan dengan peran pengasuh atau orang tua dari ibu tersebut sehingga bisa mempengaruhi hasil skor kuesioner sikap.

Berdasarkan analisis bivariat dengan ujichi square dengan hasil signifikansi sebesar 0,669 ( $\mathrm{p}>$ 0,05 ), artinya tidak ditemukan hubungan yang bermakna antara tingkat pendapatan terhadap kelengkapan imunisasi. Hal ini sejalan dengan penelitian yang dilakukan oleh Rahmawati (2014) bahwa tidak ditemukan pengaruh antara tingkat pendapatan dengan kelengkapan imunisasi. Pada penelitian yang dilaksanakan di wilayah Krembangan utara tersebut dijelaskan sebagian besar masyarakat menggunakan fasilitas yang diberikan pemerintah seperti posyandu sehingga tidak ada biaya yang dikeluarkan oleh orangtua untuk memberikan imunisasi pada anaknya karena imunisasi yang berasal dari pemerintah diberikan secara gratis untuk masyarakat. Menurut departemen kesehatan Republik Indonesia tahun 2013 tentang penyelenggaraan imunisasi menegaskan pada bagian kelima pasal 23 disebutkan bahwa pemerintah daerah kabupaten/kota bertanggungjawab menyiapkan biaya operasional untuk pelaksanaan pelayanan imunisasi wajib berupa transport dan akomodasi petugas, bahan habis pakai, penggerakan masyarakat, serta pemeliharaan dan perbaikan peralatan rantai vaksin. Disebutkan pula oleh sistem jaminan kesehatan BPJS bahwa jenis vaksin yang disediakan pemerintah berupa vaksin BCG, polio, campak, DPT-Hib, sedangkan HB0 diikutsertakan pada paket bayi baru lahir (BPJS, 2014).

Berdasarkan penelitian yang dilakukan, diketahui dari total 84 responden dibagi 42 responden $(50 \%)$ pada kelompok dropout imunisasi tidak hadir pada saat imunisasi dan 42 responden $(50 \%)$ pada kelompok imunisasi lengkap hadir pada penyelenggaraan imunisasi. Data ini telah menunjukkan bahwa semua bayi yang tidak hadir 
pada saat imunisasi masuk ke dalam kategori drop out dan semua bayi yang hadir masuk dalam kategori imunisasi lengkap sehingga dapat dipastikan bahwa apabila bayi tersebut hadir pada saat penyelenggaraan imunisasi maka bayi tersebut akan memperoleh imunisasi yang lengkap. Berdasarkan kuesioner pada kelompok drop out imunisasi ditemukan alasan terbanyak bayi yang tidak datang karena alasan lupa 32 responden (77\%), sibuk bekerja 8 responden $(19 \%)$, dan sakit 2 responden $(4 \%)$.

Berdasarkan analisis bivariat dengan ujichi squaredengan nilai signifikansi sebesar 0,309 ( $>>0,05)$, artinya tidak ditemukan hubungan antara pendidikan terhadap kelengkapan imunisasi. Hal ini dikarenakan distribusi ibu dengan tingkat pendidikan yang tinggi, sedang, dan rendah pada kategori dropout dan imunisasi lengkap pada penelitian ini tidak merata.

Hal ini tidak sesuai dengan penelitian yang dilakukan oleh Rizani (2009) yang menunjukkan bahwa tingkat pendidikan berhubungan dengan perilaku ibu dalam pemberian imunisasi. Tingkat pendidikan menggambarkan tingkat kematangan seseorang dalam merespon lingkungan sehingga dapat mempengaruhi wawasan berpikir atau merespon pengetahuan yang ada di sekitarnya. Semakin tinggi tingkat pendidikan seseorang maka semakin besar peluang untuk mendapatkan informasi yang dapat mempunyai pengertian lebih baik tentang pencegahan penyakit dan mempunyai kesadaran lebih tinggi terhadap masalah-masalah kesehatan (Rizani, 2009).

Pendidikan merupakan salah satu faktor yang sangat penting dalam menentukan perilaku ibu, karena seorang ibu dengan berpendidikan tinggi akan mempengaruhi kesehatan keluarganya, sebab banyak informasi yang diperoleh di sekolah, tapi apabila seseorang berpendidikan rendah, maka diharapkan ia dapat menambah informasinya dari sumber lainnya di luar dari pendidikan formal atau disebut jalur informal seperti melalui media elektronik (televisi, radio, internet), membaca koran, atau majalah (Rizani,2009).

\section{KESIMPULAN}

Berdasarkan hasil serta pembahasan dalam penelitian ini dapat ditarik kesimpulan sebagai berikut:
1. Jumlah bayi dengan status imunisasi dasar tidak lengkap (dropout) wilayah kerja puskesmas X Kediri pada periode tahun 2015 hingga Juli 2016 sebanyak 42 bayi.

2. Usia Ibu mempengaruhi status kelengkapan imunisasi dasar pada bayi di wilayah kerja puskesmas X Kota Kediri.

3. Pekerjaan Ibu mempengaruhi status kelengkapan imunisasi dasar pada bayi di wilayah kerja puskesmas X Kota Kediri.

4. Pengetahuan Ibu mempengaruhi status kelengkapan imunisasi dasar pada bayi di wilayah kerja puskesmas X Kota Kediri.

5. Kehadiran balita mempengaruhi status kelengkapan imunisasi dasar pada bayi di wilayah kerja puskesmas X Kota Kediri.

6. Faktor Pendidikan, Pendapatan, Sikap Ibu, dan Peran petugas kesehatan tidak mempengaruhi status kelengkapan imunisasi dasar pada bayi di wilayah kerja puskesmas X Kota Kediri.

\section{DAFTAR PUSTAKA}

Albertina, Mathilda, et.al.2009.Kelengkapan Imunisasi Dasar Anak Balita dan faktor-Fktor yang Berbubungan di Poliklinik. Anak Beberapa Rumah Sakit di Jakarta dan Sekitarnya pada Bulan Maret 2008. Departemen Ilmu Kesehatan Anak Fakultas Kedokteran Universitas Indonesia RS Dr.Cipto Mangunkusumo,Jakarta:Sari Pediatri

Ali, Muhammad.2003. Pengetabuan, Sikap, dan Perilaku Ibu Bekerja dan Ibu Tidak Bekerja tentang Imunisasi. Tesis Bagian Ilmu Kesehatan Anak Fakultas Kedokteran UniversitasSumatera Utara.

BPJS Kesehatan.2014.Panduan Praktis Pelayanan Imunisasi.BJPS Kesehatan

Dashan, Kailas, et.al.2014.IAP Guidebook on Immunization 2013-14.Indian Academy Of Pediatrics.

Departemen Kesehatan.2007.Buletin data Surveilans PD3I : Penyakit Dapat dicegah Dengan Imunisasi.Departemen Kesehatan.

Dinas Kesehatan Kota Kediri.2015.Profil Kesehatan Kota Kediri Tabun 2015.Dinas Kesehatan.

Dinas Kesehatan Provinsi Bali.2013.Profil Kesehatan Provinsi Bali.Bali:Dinas Kesehatan 


\section{VOLUME 12 NOMOR 2 DESEMBER 2016}

Dinas Kesehatan.2010.Keputusan Menteri Kesehatan Republik. Indonesia Nomor: 482/MENKES/ SK/IV/2010 : Gerakan Akselarasi Imunisasi Nasional Universal Child Immunization 20102014 (GAIN UCI 2010-2014). Menteri Kesehatan Republik Indonesia.

Dinas Kesehatan.2013.Peraturan Menteri Kesehatan Republik Indonesia Nomor 42 Tabun 2013 : Penyelenggaraan Imunisasi.Menteri Kesehatan Republik Indonesia.

Dinas Kesehatan.2014.Profil Kesehatan Indonesia.Jakarta:Dinas Kesehatan.

Hadinegoro,Sri Rezeki S.2000.Kejadian Ikutan Pasca Imunisasi.Sari Pediatri.

Nainggolan,Putra.2012. Kuesioner Penelitian Hubungan Perilaku Ibu Dengan Peran Petugas Kesehatan Dalam Pemberian Imunisasi di Wilayah Kerja Puskesmas Namorambe Kecamatan Deli Tua Tabun 2012.Universitas Sumetra Utara.

Nugroho, Pratamadhita Janu.2012.Hubungan Tingkat Pengetabuan, Usia dan Pekerjaan Ibu Dengan Status Imunisasi Dasar Bayi di Desa Japanan Kecamatan Cawas Kabupaten Klaten Tabun 2012.Surakarta:Fakultas Ilmu Kesehatan Universitas Muhammadiyah Surakarta.

Pudjiadi, et al., 2009. Pedoman pelayanan medis Indonesia. Ikatan Dokter Anak Indonesia (IDAI)

Rahmawati,Adzaniyah Isyani, et.al.2014.Faktor Yang Mempengarubi Kelengkapan Imunisasi Dasar Di Keluraban Krembangan Utara. Surabaya: Departemen Epidemiologi Fakultas Kesehatan Masyarakat Universitas Airlangga.

World Health Organization.2015.Information Sheet Observed Rate Of vaccine TReactions Diphteria, Pertussis, Tetanus Vaccines.Switzerland: Global Vaccine Safety Essential Medicines \& Health Product 